\section{Transcutaneous fiber optic Raman spectroscopy of bone using annular illumination and a circular array of collection fibers}

\author{
Matthew V. Schulmerich, ${ }^{a}$ Kathryn A. Dooley, \\ Michael D. Morris, ${ }^{a, *}$ Thomas M. Vanasse, ${ }^{b}$ and \\ Steven A. Goldstein ${ }^{b}$ \\ aUniversity of Michigan, Department of Chemistry, Ann \\ Arbor, Michigan 48109-1055 \\ ${ }^{b}$ University of Michigan Medical School, Orthopaedic \\ Research Laboratories, Ann Arbor, MI 48109-2200
}

\begin{abstract}
Transcutaneous bone Raman spectroscopy with an exciting annulus of 785-nm laser light surrounding the field of view of a circular array of collection fibers is demonstrated. The configuration provides distributed laser light. The annulus is located 2 to $3 \mathrm{~mm}$ beyond the edge of the field of view of the collection fibers to reject contributions from skin and other overlying tissues. Data are presented for rat and chicken tissue. For rat tibia, the carbonate/phosphate ratio measured at a depth of $1 \mathrm{~mm}$ below the skin is in error by $2.3 \%$ at an integration time of $120 \mathrm{~s}$ and within $10 \%$ at a $30-\mathrm{s}$ integration time. For chicken tibia $4 \mathrm{~mm}$ below the skin surface, the error is less than 8\% with a 120-s integration time. () 2006 Society of Photo-Optical Instrumentation Engineers. [DOI: 10.1117/1.2400233]
\end{abstract}

Keywords: Raman spectroscopy; fiber optic probes; tissues; bones; scattering.

Paper 06205LR received Aug. 1, 2006; revised manuscript received Sep. 6, 2006; accepted for publication Sep. 18, 2006; published online Dec. 13, 2006.

Dual energy x-ray absorptiometry (DEXA) has revolutionized the diagnosis and treatment of osteoporosis, a disorder characterized by loss of bone mass and quality resulting in more than 1 million fractures per year in the United States, causing disability and even death. DEXA measures only bone mineral density and not bone quality, a term that encompasses bone architecture, material properties, and remodeling dynamics. It thus predicts only 60 to $70 \%$ of fracture risk. There is significant overlap in measurements of bone mineral density between individuals with and without fractures. ${ }^{1-3}$ DEXA also grossly underpredicts the influence of drugs used to treat osteoporosis. $^{4}$

The limitations of DEXA have fueled the search for new diagnostic and monitoring technologies. We used Raman microscopic imaging of trabecular bone (density and age matched) from the proximal femur to distinguish between tissue from females who had suffered osteoporotic fracture and those who died from causes unrelated to bone tissue problems. ${ }^{5}$ Iliac crest biopsies from females with and without the clinical diagnosis of osteoporosis were also evaluated. The

\footnotetext{
*Tel: +1-734-764-7360; E-mail: mdmorris@umich.edu
}

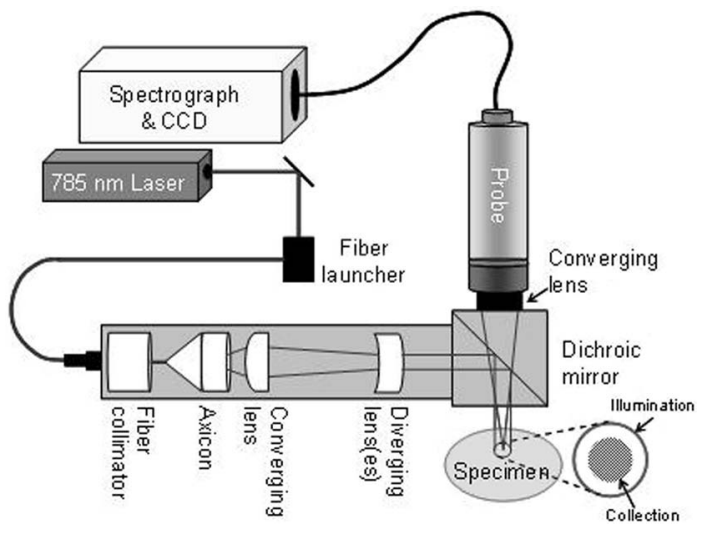

Fig. 1 Schematic of fiber optic Raman system. The components are as marked in the figure. Lenses of different focal lengths were used to adjust dimensions of illuminating annulus as needed. The drawing is not to scale.

best predictor for osteoporosis was the carbonate/phosphate ratio at the periosteal surface of the biopsy specimens. Matrix bands were less predictive because the archived specimens were fixed and embedded in polymethyl methacrylate which can partially denature proteins.

The role of diffusive light transport in highly scattering systems is widely known in biomedical optics, ${ }^{8,9}$ but was not fully appreciated by the Raman community until recently. ${ }^{10-12}$ As in other spectroscopies, fiber optic Raman probes can be used to gather subsurface information from highly scattering specimens if the detecting fibers are located some distance from the point(s) of introduction of the exciting laser light. ${ }^{13}$

We have used a probe with distributed laser light (250 to $270 \mathrm{~mW}$ ) and an array of collection fibers ${ }^{14}$ to recover bone tissue spectra in cadaveric human tissue ${ }^{15}$ at depths of $3 \mathrm{~mm}$. We have used glycerol optical clearing ${ }^{16}$ to improve transcutaneous signal recovery. ${ }^{17}$ Using a probe with two concentric rings of collection fibers and a single illumination fiber Matousek et al. demonstrated in vivo transcutaneous Raman spectroscopy of phalanges of human volunteers. ${ }^{18}$

Here we demonstrate transcutaneous Raman spectroscopy using a fiber optic probe with an axicon/lens doublet ${ }^{19}$ that distributes laser power in an annulus surrounding the field of view of a circular array of 50 collection fibers. In our previously reported global illumination configuration, which enabled subsurface mapping, coincidence of the illumination region and the field of view emphasized Raman scatter arising from the surface or close to the surface of the specimen. A completely offset collection region results in a higher ratio of subsurface to surface spectra, ${ }^{13,20}$ enhancing contrast at the cost of losing subsurface spatial information.

Figure 1 is a schematic of the probe. A 785-nm diode laser (Invictus, Kaiser Optical Systems, Ann Arbor, Michigan) is focused into a $62.5-\mu \mathrm{m}$ core-fused silica fiber, which is collimated and focused into a fused silica axicon (cone angle 179.5 deg, Delmar Photonics, San Diego, California). A planoconvex and negative-focal-length fused silica lenses focus the beam to an annulus. A dichroic mirror aligns the annulus to the field of view of the collection fibers (PhAT probe, Kai-

1083-3668/2006/11(6)/060502/3/\$22.00 @ 2006 SPIE 


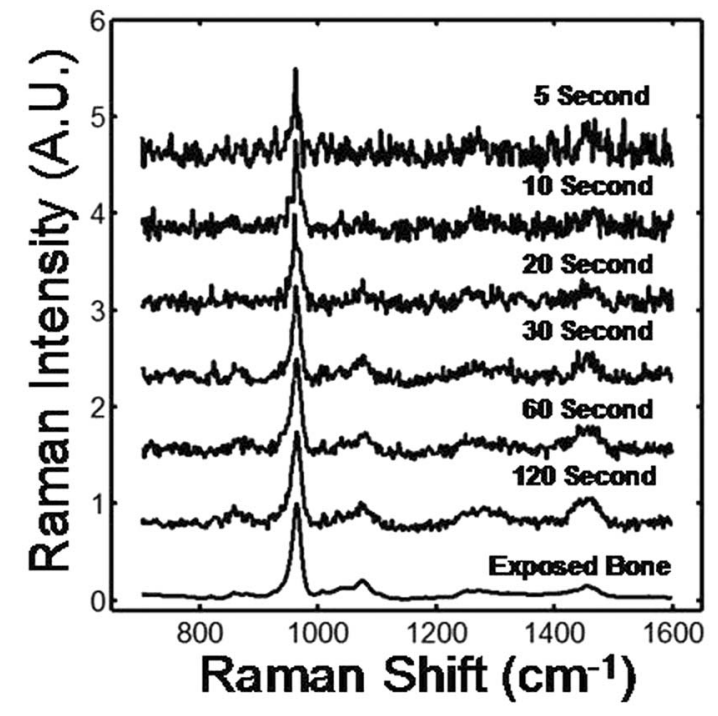

Fig. 2 Transcutaneous Raman spectra of rat tibia. The spectrum integration times are shown in the figure. The bands are phosphate, $958 \mathrm{~cm}^{-1}$; carbonate, $1070 \mathrm{~cm}^{-1}$; amide III, 1240 to $1270 \mathrm{~cm}^{-1}$; matrix $\mathrm{CH}_{2}$ deformation, $1446 \mathrm{~cm}^{-1}$.

ser Optical Systems). The assembly is mounted on the distal end of the PhAT probe. The PhAT probe output is presented to an imaging spectrograph (HoloSpec, Kaiser Optical Systems). The dispersed Raman scatter is imaged onto a $1024 \times 256$ back-illuminated deep-depletion CCD (Andor Classic, Andor Technologies, Belfast, United Kingdom) and analyzed by band target entropy minimization (BTEM). ${ }^{14}$ Band height ratios were calculated in GRAMS/AI (Thermo Galactic, Madison, Wisconsin). At the probe head the laser beam was about $110 \mathrm{~mW}$ (chicken) and $170 \mathrm{~mW}$ (rat).

Sprague-Dawley rat tibiae and femora were used to study integration time dependence. Measurements were made at an overlying skin thickness of approximately $1 \mathrm{~mm}$ using integration times between 5 and 120 s. Depilatory lotion was used to remove hair from the rat skin. Chicken tibiae were used to study penetration at a depth of 2 and $4 \mathrm{~mm}$. For all specimens, tissues were treated with an optical clearing agent, glycerol, for approximately $1 \mathrm{~min}$ before the start of each experiment, and after completing a sequence of measurements, the overlying tissue was removed and Raman spectra of the exposed bone were collected with the PhAT probe.

Figure 2 shows recovered rat tibia spectra as a function of integration time. The spectra are presented as recovered by BTEM without low-pass filtering or smoothing. The mineral spectrum recovery is good above about $30 \mathrm{~s}$. The intense phosphate $\nu_{1}$ band is visible, though distorted, even at integration times as low as $5 \mathrm{~s}$. As Table 1 shows, it is possible to obtain reasonable agreement of carbonate/phosphate ratios between measurements made on exposed bone and through $1 \mathrm{~mm}$ of skin at integration times of $30 \mathrm{~s}$ or longer. BTEM did not completely separate the skin spectrum from the bone spectrum. Amide III and the $\mathrm{CH}_{2}$ bending mode at ca. $1446 \mathrm{~cm}^{-1}$ are about four times larger in the recovered spectra than in the spectrum of exposed bone. Incomplete separation results from oversampling the skin spectrum. In these experiments the annulus outer and inner diameters were about
Table 1 Carbonate/phosphate ratios measured transcutaneously and on exposed bone.

\begin{tabular}{|c|c|c|c|c|}
\hline Specimen & $\begin{array}{c}\text { Depth } \\
(\mathrm{mm})\end{array}$ & $\begin{array}{l}\text { Acquisition } \\
\text { Time } \\
\text { (s) }\end{array}$ & $\begin{array}{c}\text { Carbonate/ } \\
\text { Phosphate } \\
\text { Ratio }\end{array}$ & $\begin{array}{c}\text { Percentage } \\
\text { Error }\end{array}$ \\
\hline \multirow[t]{7}{*}{ Rat tibia } & 0 & 60 & $0.215^{a}$ & \\
\hline & 1 & 120 & $0.220^{b}$ & 2.3 \\
\hline & 1 & 60 & $0.201^{b}$ & -6.6 \\
\hline & 1 & 30 & $0.236^{b}$ & 9.6 \\
\hline & 1 & 20 & $0.250^{b}$ & 16.4 \\
\hline & 1 & 10 & $0.098^{b}$ & -54.3 \\
\hline & 1 & 5 & NA & NA \\
\hline \multirow[t]{2}{*}{ Rat femur } & 0 & 60 & $0.222^{a}$ & \\
\hline & 2 & 120 & $0.210^{b}$ & -5.4 \\
\hline \multirow[t]{3}{*}{ Chicken tibia } & 0 & 60 & $0.225^{a}$ & \\
\hline & 2 & 120 & $0.214^{b}$ & -4.9 \\
\hline & 2 & 120 & $0.133^{c}$ & -40.9 \\
\hline \multirow[t]{3}{*}{ Chicken tibia } & 0 & 60 & $0.202^{a}$ & \\
\hline & 4 & 120 & $0.226^{b}$ & 11.8 \\
\hline & 4 & 120 & $0.218^{c}$ & 7.6 \\
\hline
\end{tabular}

${ }^{a}$ Calculated as height ratio of 1070 to $958 \mathrm{~cm}^{-1}$ bands.

batio calculated using data from all collection fibers.

"Ratio calculated without using data from the outer ring of fibers.

7 and $6 \mathrm{~mm}$ and the collection fiber field of view about $3 \mathrm{~mm}$. It was not possible with the available optics to generate a collection diameter below $3 \mathrm{~mm}$. Increasing the annulus i.d. to larger than $7 \mathrm{~mm}$ to reduce contribution from skin caused a large fraction of laser light to miss the tibia entirely.

We collected spectra of chicken tibiae using the same excitation annulus. Figure 3 shows the recovered and corresponding exposed bone spectra at depth of $4 \mathrm{~mm}$ (120-s integration time), and also the average spectrum (dotted line) collected by the probe. The spectra have not been smoothed or filtered. Figure 3(a) shows the effect of using all 50 collection fibers for BTEM calculations. Comparison of the recovered spectrum with the exposed bone spectrum shows incomplete separation of the bone factor from the overlying tissue spectrum. This is most easily seen as the erroneously high intensity of the $\mathrm{CH}_{2} 1446-\mathrm{cm}^{-1}$ band. As Table 1 shows, at a 4-mm depth, the error in measurement of carbonate/ phosphate is $11.8 \%$. If the outer ring of 18 collection fibers is excluded from the calculation, the recovery of the bone factor is improved [Fig. 3(b)] and the error is reduced to $7.6 \%$ because the operation is equivalent to increasing the distance between excitation annulus and collection fibers. SNR is not improved because the number of spectra included in the calculation is reduced.

These preliminary results can be substantially improved by optimization of the design based on realistic modeling of the 


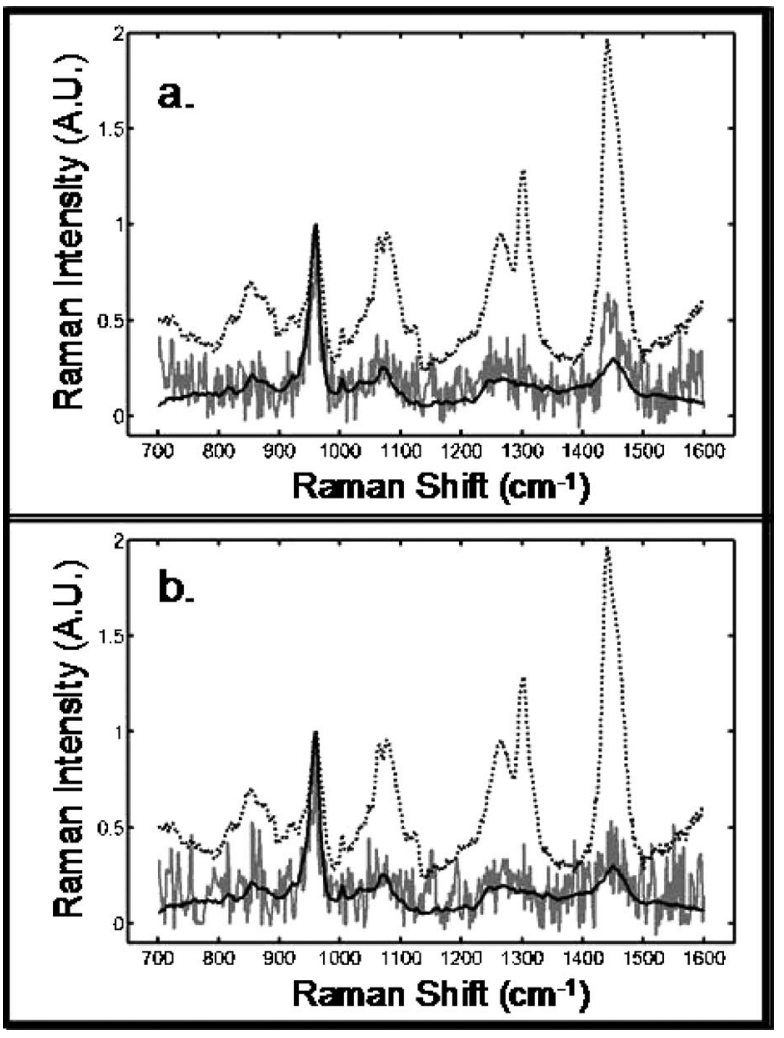

Fig. 3 Measurements made through $4 \mathrm{~mm}$ of overlying tissue on a chicken tibia at the mid diaphysis. Transcutaneous (dotted), recovered bone factor (gray), exposed bone (black): (a) recovered bone factor using data from all 50 collection fibers and (b) recovered bone factor using data from the 32 innermost collection fibers.

tissue optics of these complex skin, bone, and connective tissue systems. While much remains to be done, Raman spectroscopy shows promise as a complement to DEXA. Periosteal surfaces may be probed noninvasively up to a few millimeters below the skin surface (e.g., distal radius, vertebrae), or minimally invasive if deeper (e.g., iliac crest). Similarly, Raman spectroscopy may be useful in diagnosis and monitoring of patients with other bone diseases or genetic defects, most of which affect bone quality.

Note that after this manuscript was submitted we learned that a similar annular illumination approach has been under independent development by P. Matousek with a manuscript reporting results in press. ${ }^{21}$

\section{Acknowledgments}

This research supported in part by the University of Michigan Musculoskeletal Core Research Center through National Institutes of Health (NIH) Grant No. P30 AR46024.

\section{References}

1. J. R. Buchanan, C. Myers, R. B. Greer, T. Lloyd, and L. A. Varano, "Assessment of the risk of vertebral fracture in menopausal women," J. Bone Jt. Surg., Am. Vol. 69, 212-218 (1987).

2. B. L. Riggs, H. W. Wahner, W. L. Dunn, R. B. Mazess, K. Offord, and L. J. Melton, "Differential changes in bone mineral density of the appendicular and axial skeleton with aging: Relationship to spinal osteoporosis," J. Clin. Invest. 67, 328-335 (1981).

3. B. L. Riggs, H. W. Wahner, E. Seeman, K. P. Offord, W. L. Dunn, R.
B. Mazess, K. A. Johnson, and L. J. d. Melton, "Changes in bone mineral density of the proximal femur and spine with aging: differences between the posteneopausal and senine osteoporosis syndromes," J. Clin. Invest. 67, 328-335 (1982).

4. P. D. Delmas and E. Seeman, "Changes in bone mineral density explain little of the reduction in vertebral or nonvertebral fracture risk with anti-resorptive therapy," Bone (N.Y.) 34, 599-604 (2004).

5. B. R. McCreadie, M. D. Morris, T.-C. Chen, D. S. Rao, W. F. Finney, E. Widjaja, and S. A. Goldstein, "Bone tissue compositional differences in women with and without osteoporotic fracture," Bone (N.Y.) (in press).

6. N. L. Pleshko, A. L. Boskey, and R. Mendelsohn, "An FT-IR microscopic investigation of the effects of tissue preservation on bone," Calcif. Tissue Int. 51, 72-77 (1992).

7. Y. Yeni, J. Yerramshetty, O. Akkus, C. Pechey, and C. Les, "Effect of fixation and embedding on Raman spectroscopic analysis of bone tissue," Calcif. Tissue Int. 78, 363-371 (2006).

8. V. Tuchin, Tissue Optics. Light Scattering Methods and Instruments for Medical Diagnosis, SPIE Press, Bellingham, WA (2000).

9. T. Vo-Dinh, Biomedical Photonics Handbook, CRC Press, Boca Raton, FL (2003).

10. N. Everall, T. Hahn, P. Matousek, and A. W. Parker, "Photon migration in Raman spectroscopy," Appl. Spectrosc. 58, 591-597 (2004).

11. N. Everall, T. Hahn, P. Matousek, A. W. Parker, and M. Towrie, "Picosecond time-resolved Raman spectroscopy of solids: capabilities and limitations for fluorescence rejection and the influence of diffuse reflectance," Appl. Spectrosc. 55, 1701-1708 (2001).

12. P. Matousek, N. Everall, M. Towrie, and A. W. Parker, "Depth profiling in diffusely scattering media using Raman spectroscopy and picosecond Kerr gating," Appl. Spectrosc. 59, 200-205 (2005).

13. P. Matousek, I. P. Clark, E. Draper, M. D. Morris, A. Goodship, N. Everall, M. Towrie, W. F. Finney, and A. W. Parker, "Subsurface probing of diffusely scattering media using spatially offset Raman spectroscopy (SORS)," Appl. Spectrosc. 59, 393-400 (2005).

14. M. V. Schulmerich, W. F. Finney, R. A. Fredericks, and M. D. Morris, "Subsurface Raman spectroscopy and mapping using a globally illuminated non-confocal fiber-optic array probe in the presence of Raman photon migration," Appl. Spectrosc. 60, 109-114 (2006).

15. M. V. Schulmerich, W. F. Finney, V. Popescu, M. D. Morris, T. M. Vanasse, and S. A. Goldstein, "Transcutaneous Raman spectroscopy of bone tissue using a nonconfocal fiber optic array probe," Proc. SPIE 6093, 609300 (2006).

16. V. V. Tuchin, Optical Clearing of Tissues and Blood, SPIE Press, Bellingham, WA (2006).

17. M. V. Schulmerich, M. D. Morris, T. M. Vanasse, and S. A. Goldstein, "Optical clearing in transcutaneous Raman spectroscopy of bone tissue" (submitted for publication).

18. P. Matousek, E. R. C. Draper, A. E. Goodship, I. P. Clark, K. L. Ronayne, and A. W. Parker, "Noninvasive Raman spectroscopy of human tissue in vivo" Appl. Spectrosc. 60, 758-763 (2006).

19. P.-A. Bélanger and M. Rioux, "Ring pattern of a lens-axicon doublet illuminated by a Gaussian beam," Appl. Opt. 17, 1080-1086 (1978).

20. P. Matousek, M. D. Morris, N. Everall, I. P. Clark, M. Towrie, E. Draper, A. Goodship, and A. W. Parker, "Numerical simulations of subsurface probing in diffusely scattering media using spatially offset Raman spectroscopy," Appl. Spectrosc. 59, 1485-1492 (2005).

21. P. Matousek, "Inverse spatially offset Raman spectroscopy for deep non-invasive probing of turbid media" Appl. Spectrosc. (in press). 